NBER WORKING PAPER SERIES

\title{
A DYNAMIC THEORY OF OPTIMAL CAPITAL STRUCTURE AND EXECUTIVE COMPENSATION
}

\author{
Andrew Atkeson \\ Harold L.Cole \\ Working Paper 11083 \\ http://www.nber.org/papers/w11083 \\ NATIONAL BUREAU OF ECONOMIC RESEARCH \\ 1050 Massachusetts Avenue \\ Cambridge, MA 02138 \\ January 2005
}

Atkeson gratefully acknowledge support from the National Science Foundation. Cole acknowledges the support of NSF SES 0137421. We thank Narayana Kocherlakota, Andrzej Skrzypacz, and Steve Tadelis for helpful comments. The views expressed herein are those of the author(s) and do not necessarily reflect the views of the National Bureau of Economic Research.

(C) 2005 by Andrew Atkeson and Harold L. Cole. All rights reserved. Short sections of text, not to exceed two paragraphs, may be quoted without explicit permission provided that full credit, including @ $\odot$ notice, is given to the source. 
A Dynamic Theory of Optimal Capital Structure and Executive Compensation Andrew Atkeson and Harold L. Cole

NBER Working Paper No. 11083

January 2005

JEL No. G3

\section{ABSTRACT}

We put forward a theory of the optimal capital structure of the firm based on Jensen's (1986) hypothesis that a firm's choice of capital structure is determined by a trade-off between agency costs and monitoring costs. We model this tradeoff dynamically. We assume that early on in the production process, outside investors face an informational friction with respect to withdrawing funds from the firm which dissipates over time. We assume that they also face an agency friction which increases over time with respect to funds left inside the firm. The problem of determining the optimal capital structure of the firm as well as the optimal compensation of the manager is then a problem of choosing payments to outside investors and the manager at each stage of production to balance these two frictions.

Andrew Atkeson

Bunche Hall 9381

Department of Economics

UCLA

Box 951477

Los Angeles, CA 90095-1477

and NBER

andy@atkeson.net

Harold Cole

Economics Department

University of California

405 Hilgard Avenue

Los Angeles, CA 90095-1477

and NBER

hlcole@econ.ucla.edu 


\section{Introduction}

We put forward a theory of the optimal capital structure of the firm and the optimal compensation of the firm's managers based on Jensen's (1986) hypothesis that a firm's choice of capital structure is determined by a trade-off between agency costs and monitoring costs. We model this trade-off dynamically by assuming that outside investors in a firm face different obstacles to recouping their investment at different times. Early on in the production process, outside investors face an information friction - the output of the firm is private information to the manager of the firm unless the outside investors pay a fixed cost to monitor the firm. With time, the output of the firm is revealed to outside investors and, hence, the information friction disappears. At this later stage in the production process however, outside investors face an agency friction - the firm's manager can divert resources not paid out to investors in the early phases of production towards perquisites that provide him with private benefits. The problem of determining the optimal capital structure of the firm as well as the optimal compensation of the manager is then a problem of choosing payments to outside investors and the manager at each stage of production to balance these two frictions.

Our theory is developed in an dynamic optimal contracting framework, and, as a result, our model yields predictions about the joint dynamics of a firm's capital structure and its executive compensation. The choice of compensation for the manager is shaped by the assumption that the manager is risk averse while the outside investors are risk neutral. Our theory has the following implications regarding optimal capital structure and executive compensation. Each period, the payouts from the firm can be divided into payments to the manager that consist of a non-contingent base pay and a performance component of pay based on the realized output of the firm, as well as two distinct payments to the outside investors 
that resemble payments to debt and outside equity respectively. The debt-like payment to outside investors is made early in the period. It comes in the form of a fixed lump - the failure of which to pay leads to monitoring. The equity-like payment to outside investors comes in the form of a residual which depends upon the performance of the firm and is paid at the end of the period.

In our model, the fact that the manager receives some form of performance based pay is not motivated by the desire to induce the manager to exert greater effort or care in managing the firm. Instead, the performance based component of the manager's pay simply serves to induce the manager to forsake expenditures on perquisites for his own enjoyment. Hence, our model's predictions for whether it is optimal to have the performance component of the manager's compensation depend on the total market value of the firm or on some narrower measure of current performance such as current sales are determined entirely by our assumptions regarding the extent of the agency friction. If the manager is able to appropriate a broad measure of the firm's resources for his own benefit, then his performance bonus will be based on this broad measure. If the manager's ability to appropriate resources is more limited in scope, then his bonus pay will be based on this narrower measure of performance.

Our theory also has implications for the relationship between the optimal financial structure of the firm and its optimal production plan. Our theory predicts that there is a wedge between the marginal product of capital in the firm and rental rate on capital that depends upon the expected monitoring costs associated with bankruptcy and the inefficient risk-sharing between outside investors and the manager induced by the agency friction. Under certain parametric assumptions, we are able to compute the magnitude of this wedge between the marginal product of capital and its rental rate in terms of readily observed features of 
the firm's financial structure and its executive compensation.

To extend our model to a dynamic setting, we assume that there is an information cycle in which outside investors first face an information friction and then face an agency friction. This cycle is repeated indefinitely. We associate this cycle with an accounting or capital budgeting cycle at the firm. We show the qualitative decomposition of the optimal contract into four payments — base pay and performance pay for the manager, and debt and equity-like payments to the outside investors — holds both in a static setting in which there is only one information cycle, and in a dynamic setting in which there are an arbitrary number of information cycles. Thus, repetition of our contracting problem does not change, qualitatively, the interpretation of our efficient contract as a theory of capital structure and executive compensation.

We derive two additional results in our model in dynamic setting with more than one information cycle. The first of these results is that the compensation of incumbent managers is non-decreasing over time, regardless of the performance of the firm. The second of these results is that incumbent managers are protected against the risk that they become unproductive with a "golden parachute".

The result that the pay of the incumbent manager is non-decreasing over time has implications for the dynamics of the firm's optimal capital structure since, ceteris paribus, the dynamics of executive compensation alter the terms of the trade-off between the information and agency frictions that outside investors face. In particular, this result implies that if the firm is particularly profitable in one period, in the next period, the firm's payout shifts away from debt toward equity.

The result that an incumbent manager that becomes unproductive receives a "golden 
parachute" sufficient to maintain the marginal utility of consumption that he enjoyed as productive manager is a direct consequence of optimal risk sharing. The exact size of the golden parachute is determined by the outside opportunities of an incumbent manager - if these outside opportunities are not good, then the manager receives a large golden parachute while if they are good, then the parachute mandated by optimal risk sharing is smaller.

Our model delivers predictions for the division of payments from the firm between the manager, the owners of outside equity, and the owners of the firm's debt based on the tradeoff of information and agency frictions. It is important to note that our dynamic model does not pin down the debt-equity ratio of the firm. This is because our model does not pin down the source of financing for ongoing investment in the firm. We present an simple example to demonstrate that, holding fixed the division of gross payments to debt and outside equity holders, the firm will have a different debt-equity ratio depending on whether debt is long term and ongoing investment is financed out of retained earnings or debt is short-term and ongoing investment is financed with new short-term debt. We conjecture that this failure of our model to pin down the debt-equity ratio of the firm in a dynamic setting may be a general aspect of completely specified "trade-off" models of corporate finance.

This paper is considers the optimal financial contract between outside investors and a manager in the presence of both information and agency frictions when there is the possibility of monitoring. It is therefore related to a wide range of prior research on each of these topics. The within period, or static, aspects of the information and monitoring aspect is similar to Townsend (1979), while the static aspects of the agency friction and the information friction are similar to Hart and Moore (1995), in that these frictions can rationalize a division of the firms output into debt, and other payments. ${ }^{1}$ However, unlike these prior papers, the 
inclusion of both frictions and monitoring, and the specific form of these friction leads to three different payment streams coming out of the firm, outside debt, outside equity, and managerial compensation.

Since we consider these frictions within a recursive environment, our paper is related to prior work on dynamic efficient contracting. However, unlike the literature on dynamic models of efficient financial contracting with information frictions, such as Atkeson (1991), Hopenhayn and Clementi (2002), Demarzo and Fishman (2004) or Wang (2004), our information friction is temporary since there is complete information revelation by the end of the period. As a result, while the costly state verification aspect of our model rationalizes outside debt, the dynamic aspects and the overall tractability of our model are similar to those of the dynamic enforcement constraint literature, such as Albuquerque and Hopenhayn (2004), and Cooley, Marimon and Quadrini (2004). In particular, it shares the feature that if the manger is retained, then his promised utility is weakly increasing over time, and these increases serve to reduce the extent of the enforcement friction.

In our model contracting is complete subject to explicit information and enforcement frictions. This is in contrast to a large literature that seeks to explain various aspects of the financial structure of firms as arising from incomplete contracting. Examples include Hart and Moore (1995,1997), as well as: Aghion and Bolton (1992) which examines the efficient allocation of control rights, Dewatripont and Tirole (1994) in which outside investors choose their holdings of a debt as opposed to equity claims to generate the efficient decision with respect to the interference or not in the continuing operation of the firm, Zweibel (1996) in which manager uses debt as a means of constraint their future investment choices to be more efficient. 


\section{Model}

We begin by presenting a one period version of the model. We extend our results to a dynamic model in a later section.

There is a large number of risk neutral outside investors who are endowed with capital which they can rent in the market at rental rate $r$. There is also a large number of identical risk averse managers. These managers have an outside opportunity that offers them utility $U_{0}$. We assume that the managers have a utility function $u(c)$ with $u(0)=-\infty$ and $u^{\prime}(0)=\infty$.

There is a production technology that transforms capital and the labor of a manager into output. The production process takes place over the course of three subperiods within the period. In the first subperiod, a manager is chosen to operate the production technology and capital $K$ is installed. In the second subperiod, this production technology yields output

$$
y=\theta F(K)
$$

where $\theta$ is a productivity shock that is idiosyncratic to this technology. In this subperiod, this productivity shock $\theta$ and hence, output $y$ as well, is private information to the manager. The set of possible shocks is an interval given by $\Theta$ and the distribution of these shocks has c.d.f. $P$ with density $p$ and an expected value of one. We assume that there are diminishing returns to scale in the sense that $F^{\prime \prime}(K)<0$.

In the second sub-period, the outside investors have the option of monitoring the output of the project to learn the realization of the shock $\theta$ (and hence output $y$ as well) at a cost of $\gamma F(K)$ units of output. At the end of the second subperiod, the manager has the option of spending up to fraction $\tau$ of whatever output of the firm that he has not paid 
out to the outside investors during this sub-period on perquisites that he alone enjoys. That output that the manager does not spend on perquisites is productively reinvested in the firm. For simplicity, we assume that the gross return on this productive reinvestment in the firm between the second and third sub-periods is one.

In the third sub-period, the outside investors can freely observe both the output of the firm $y=\theta F(K)$ and the division of this output between spending on perks for the manager and productive reinvestment.

The contracting problem between the outside investors and the manager can be described as follows. A contract between these parties specifies a level of capital $K$ to be hired in the first subperiod, a decision by the outside investors to monitor $m$ and a payment from the manager to the outside investors in the second subperiod $v$, and a payment from the outside investors to the manager in the third subperiod $x$.

We assume that the outside investors can commit to a deterministic strategy for paying the cost to monitor the output of the project in the second sub-period as a function of the manager's announcement $\hat{\theta}$ of the realization of the productivity shock $\theta$. Denote this strategy by $m(\hat{\theta})$ and denote set of announced shocks for which monitoring takes place by $M \subseteq \Theta$.

The payments $v$ from the manager to the outside investors in the second subperiod are contingent on the manager's announcement of the productivity shock $\hat{\theta}$ as well as the outcome of the monitoring decision. Let $v_{0}(\hat{\theta})$ denote the payment that the manager makes to the outside investors in the second sub-period as a function of the announcement $\hat{\theta}$ in case monitoring does not take place, and let $v_{1}(\hat{\theta}, \theta)$ denote the payment that the manager makes as a function both of the announcement $\hat{\theta}$ and the true value of $\theta$ in case monitoring does take place. 
Finally, let $x(\hat{\theta}, \theta)$ denote the payment from the outside investors to the manager in the third subperiod as a function of his report $\hat{\theta}$ in the second sub-period and the realized production shock $\theta$. Note that it is not necessary for $x$ to depend on the monitoring decision because the true value of $\theta$ is revealed to outside investors in the third sub-period at zero cost.

For reasons of limited liability, we require

$$
v_{0}(\hat{\theta}) \leq \hat{\theta} F(K), v_{1}(\hat{\theta}, \theta) \leq \theta F(K) \text {, and } x(\hat{\theta}, \theta) \geq 0 .
$$

We assume, without loss of generality, that $x(\hat{\theta}, \theta)$ is chosen to ensure that the manager chooses not to take any perks for himself. This assumption implies a constraint on $x(\hat{\theta}, \theta)$ that

$$
\begin{aligned}
& u(x(\hat{\theta}, \theta)) \geq u\left(\tau\left(\theta F(K)-v_{0}(\hat{\theta})\right)\right) \text { for all } \hat{\theta} \notin M, \text { and } \\
& u(x(\hat{\theta}, \theta)) \geq u\left(\tau\left(\theta F(K)-v_{1}(\hat{\theta}, \theta)\right)\right) \text { for all } \hat{\theta} \in M .
\end{aligned}
$$

Given the terms of the contract, $m, v_{0}, v_{1}$, and $x$, the manager chooses a strategy for reporting $\theta$ denoted $\sigma(\theta)$. We say that the report $\sigma(\theta)=\hat{\theta}$ is feasible given $v_{0}$ and $\theta$ if either $\hat{\theta} \in M$ or $\hat{\theta} \notin M$ and $v_{0}(\hat{\theta}) \leq \theta F(K)$. Note that this definition requires that the manager has the resources to make the payment $v_{0}(\sigma(\theta))$ in the event that he reports $\sigma(\theta)=\hat{\theta} \notin M$. We restrict the manager to choose a reporting strategies such that $\sigma(\theta)$ is feasible given $v_{0}$ for all $\theta$. We interpret this constraint as following from the assumption that there is an optimal contract in which the outside investors choose to monitor if the manager announces $\hat{\theta} \notin M$ 
but then does not pay $v_{0}(\hat{\theta})$ and that $x(\hat{\theta}, \theta)=0$ in this event.

We restrict attention to contracts in which the manager truthfully reports $\theta$. Hence, we impose the incentive constraint

$$
u(x(\theta, \theta)) \geq u(x(\hat{\theta}, \theta)) \text { for all } \theta \in \Theta \text { and feasible } \hat{\theta} \text { given } \theta \text { and } v_{0}
$$

The manager's expected utility under the contract is given by the expectation of $u(x(\theta, \theta))$. Since managers have an outside opportunity that delivers them utility $U_{0}$, we require the individual rationality constraint

$$
\int u(x(\theta, \theta)) p(\theta) d \theta \geq U_{0}
$$

Note that this contracting problem is a partial equilibrium problem in the sense we assume that the outside investors have already purchased this production opportunity from the entrepreneur who created it and now they simply seek to design a contract with the manager that they hire on a competitive market to run this production opportunity. We do not model the costs that entrepreneurs pay to create these production opportunities nor the price that they receive when they sell a newly created production opportunity to outside investors. 


\section{Characterizing an efficient contract}

In this section, we characterize a contract that maximizes the expected payoff to the outside investors

$$
\int[(\theta-\gamma m(\theta)) F(K)-x(\theta, \theta)] p(\theta) d \theta-r K
$$

subject to the constraints (1), (2), (3), and (4) in the following two propositions. We refer to such a contract as an efficient contract.

Proposition 1. There is an efficient contract with the following properties: $(i) v_{1}(\hat{\theta}, \theta)=$ $\theta F(K)$ for all $\hat{\theta} \in M$ and $v_{0}(\hat{\theta})=\theta^{*} F(K)$ for all $\hat{\theta} \notin M$, where $\theta^{*}=\inf \{\hat{\theta} \mid \hat{\theta} \notin M\}$, (ii) $M$ is an interval ranging from 0 to $\theta^{*}$, and (iii) for $\hat{\theta} \neq \theta, x(\hat{\theta}, \theta)=0$ if $\hat{\theta} \leq \theta^{*}$ and $x(\hat{\theta}, \theta)=\tau\left(\theta-\theta^{*}\right) F(K)$ if $\theta>\theta^{*}$.

Proof: To prove $(i)$, we first consider the case of reports that lead to monitoring. For all $\hat{\theta} \in M$, setting $v_{1}(\hat{\theta}, \theta)=\theta F(K)$ relaxes the constraint (2) as much as possible and has no effect on the objective (5) nor on any other constraint. Hence we can, without loss of generality, assume that $v_{1}$ has this form.

Next, consider the case of reports that don't lead to monitoring. Let $v_{0}^{*}=\inf \left\{v_{0}(\hat{\theta}) \mid \hat{\theta} \notin M\right\}$.

Note that for all $\theta<v_{0}^{*} / F(K)$, it is not feasible for the manager to report $\hat{\theta} \notin M$ since the manager would be unable to make the payment $v_{0}(\hat{\theta}) \geq v_{0}^{*}$ in that case. This implies that $v_{0}^{*} \leq \theta F(K)$ for all $\theta \notin M$ since, otherwise, truthtelling would not be feasible. From (2) and 
(3), for all $\theta \geq v_{0}^{*} / F(K)$, we have that

$$
x(\theta, \theta) \geq \sup _{\hat{\theta} \notin M} x(\hat{\theta}, \theta) \geq \tau\left(\theta F(K)-v_{0}^{*}\right)
$$

since the manager can, with strategic reporting of $\hat{\theta}$, ensure that the payment that he makes to outside investors in the second subperiod is arbitrarily close to $v_{0}^{*}$ and thus ensure that he consumes arbitrarily close to $\tau\left(\theta F(K)-v_{0}^{*}\right)$ in perks. Since $\left(\theta F(K)-v_{0}^{*}\right) \geq\left(\theta F(K)-v_{0}(\hat{\theta})\right)$ for all $\hat{\theta} \notin M$, we can set $v_{0}(\hat{\theta})$ equal to a constant, here $v_{0}^{*}$, without affecting any of the binding incentive constraints (2). Given a monitoring set $M$, setting the constant $v_{0}^{*}$ as high as possible relaxes the constraint (2) as much as possible. Given this, constraint (1) implies that $v_{0}^{*}=\theta^{*} F(K)$ with $\theta^{*} \equiv \inf \{\hat{\theta} \mid \hat{\theta} \notin M\}$ is an optimal choice.

To prove that $M$ is an interval, note that if $M$ were to contain some $\tilde{\theta}>\theta^{*}$, it would still be the case that, for that $\tilde{\theta}, x(\tilde{\theta}, \tilde{\theta}) \geq \tau\left(\tilde{\theta}-\theta^{*}\right) F(K)$ since the manager has the option of reporting any feasible $\hat{\theta} \notin M$ that he chooses and hence ensuring himself of consumption arbitrarily close to $\tau\left(\tilde{\theta}-\theta^{*}\right) F(K)$. Hence, it is not possible to relax the constraint $(2)$ for $\theta>\theta^{*}$ any further by choosing to monitor for that report $\tilde{\theta}$. Since it is costly to monitor, an efficient contract must have $\tilde{\theta} \notin M$ for almost all $\tilde{\theta}>\theta^{*}$. Thus, there is an efficient contract in which $M$ is an interval ranging from 0 to $\theta^{*}$.

To finish the proof, observe that given the incentive constraint (3), we can, without loss of generality, set $x(\hat{\theta}, \theta)$ for $\hat{\theta} \neq \theta$ as low as possible to relax this incentive constraint as much as possible. Hence, it is efficient to set $x(\hat{\theta}, \theta)=0$ for $\hat{\theta} \neq \theta$ and $\hat{\theta} \leq \theta^{*}$, and it is feasible to do so since, in the event of monitoring, the outside investors take possession of the output of the firm and there are no resources for the manager to spend on perks for 
himself. From (2) and the results above, we set $x(\hat{\theta}, \theta)=\tau\left(\theta-\theta^{*}\right)$ for $\hat{\theta} \neq \theta$ and $\hat{\theta}>\theta^{*}$. Here it is not possible to set the manager's compensation any lower. Note that by setting $x(\hat{\theta}, \theta)$ in this way, we ensure that any choice of $x(\theta, \theta)$ that satisfies nonnegativity for $\theta \leq \theta^{*}$ and $x(\theta, \theta) \geq \tau\left(\theta-\theta^{*}\right) F(K)$ for $\theta>\theta^{*}$ also satisfies both the no perks condition (2) and is incentive compatible in that it satisfies (3). Q.E.D.

With these results, we can restate our optimal contracting problem much more simply as follows. The problem now is to choose a level of investment $K$, a monitoring set indexed by $\theta^{*}$, and payments to the manager $w(\theta)=x(\theta, \theta)$ to maximize the expected payoff to the outside investors:

$$
\int(\theta F(K)-w(\theta)) p(\theta) d \theta-\gamma P\left(\theta^{*}\right) F(K)-r K
$$

subject to the constraints of individual rationality

$$
\int u(w(\theta)) p(\theta) d \theta \geq U_{0}
$$

and a no-perks constraint

$$
u(w(\theta)) \geq u\left(\tau\left(\theta-\theta^{*}\right) F(K)\right) \text { for all } \theta \geq \theta^{*}
$$

With our assumption that managers' utility is unbounded below, we know that the limited liability constraint $w(\theta) \geq 0$ is not binding.

Given values of $\theta^{*}, K$, and $w(\theta)$ that solve this problem, the contract with $M=$ $\left\{\theta \mid \theta \leq \theta^{*}\right\}, v_{1}(\hat{\theta}, \theta)=\theta F(K), v_{0}(\hat{\theta})=\theta^{*} F(K), x(\theta, \theta)=w(\theta), x(\hat{\theta}, \theta)=0$ for $\hat{\theta} \neq \theta$ and 
$\hat{\theta} \leq \theta^{*}$, and $x(\hat{\theta}, \theta)=\tau\left(\theta-\theta^{*}\right) F(K)$ for $\hat{\theta} \neq \theta$ and $\hat{\theta}>\theta^{*}$ is an efficient contract.

In the following two sections, we use the first order conditions of this simplified contracting problem to characterize the financial structure of this project and the relationship between financial structure and production efficiency. To that end, we consider the Lagrangian associated with the problem (7) given by

$$
\begin{aligned}
& \max _{w(\theta), K, \theta^{*}, \lambda, \delta(\theta)} \int(\theta F(K)-w(\theta)) p(\theta) d \theta-\gamma P\left(\theta^{*}\right) F(K)-r K+ \\
& \lambda\left\{\int u(w(\theta)) p(\theta) d \theta-U_{0}\right\}+ \\
& \int \delta(\theta)\left\{u(w(\theta))-u\left(\tau\left(\theta-\theta^{*}\right) F(K)\right)\right\} p(\theta) d \theta .
\end{aligned}
$$

\section{Debt, Equity and Executive Compensation}

In this section, we interpret the characteristics of the efficient contract in terms of a contract compensating the manager that consists of a base level of pay and a performance bonus, a debt contract, and an outside equity contract.

We begin by characterizing managerial compensation under this optimal contract in the following proposition.

Proposition 2. Under an optimal contract, the payments to the manager $w(\theta)$ have the form $w(\theta)=\bar{w}$ for $\theta \leq \bar{\theta}$ and $w(\theta)=\tau\left(\theta-\theta^{*}\right) F(K)$ for $\theta>\bar{\theta}$, where $\bar{\theta}$ is the solution to $\bar{w}=\tau\left(\bar{\theta}-\theta^{*}\right) F(K)$. 
Proof: The first-order conditions of (10) with respect to $w(\theta)$ are given by

$$
1=(\lambda+\delta(\theta)) u^{\prime}(w(\theta))
$$

This first order condition implies that $w(\theta)$ is constant for all values of $\theta$ such that the constraint $(9)$ does not bind $(\delta(\theta)=0)$. We denote this constant by $\bar{w}$. Given $\bar{w}$, the constraint (9) binds for $\theta>\bar{\theta}$ and does not bind for $\theta<\bar{\theta}$. Clearly, $w(\theta)=\tau\left(\theta-\theta^{*}\right) F(K)$ when (9) binds. Q.E.D.

Note that for those values of $\theta$ such that the constraint (9) is slack, the first order condition (11) implies that

$$
\lambda=\frac{1}{u^{\prime}(\bar{w})}
$$

From proposition 2, we have that the payments made to the manager in the third sub-period are given by $w(\theta)=\bar{w}$ in the event that $\theta \leq \bar{\theta}$ and $w(\theta)=\tau\left(\theta-\theta^{*}\right) F(K)=$ $\tau(\theta-\bar{\theta}) F(K)+\bar{w}$ in the event that $\theta>\bar{\theta}$. We interpret the payment $\bar{w}$ as the manager's base pay and the additional payment to the manager of $\tau(\theta-\bar{\theta}) F(K)$ in the event that $\theta>\bar{\theta}$ as the performance component of the manager's pay. For the outside investors, the value of this performance payment to the manager is given by

$$
C=\left[\int_{\bar{\theta}}^{\infty} \tau(\theta-\bar{\theta}) p(\theta) d \theta\right] F(K) .
$$

Note that the manager places a different value on these payments because he is risk averse. As we discus below, this wedge between the valuation of this performance payment by the 
outside investors and the manager plays a role in determining the firm's optimal production plan.

To interpret the other payments under this optimal contract in terms of debt and equity, we must ensure that payments to outside investors after the initial investment in the first sub-period are non-negative so that they do not violate the limited liability constraint imposed on investors in corporations. To do so, we assume that the outside investors invest not only the capital $K$, but also the uncontingent portion of the manager's pay $\bar{w}$ in the first sub-period. We associate the payments $v_{0}$ or $v_{1}$ made by the manager in the second sub-period as the payments to debt holders. We associate the residual payments to outside investors as the payments to outside equity.

The payments made in the second sub-period are given by $v_{1}(\theta, \theta)=\theta F(K)$ if $\theta \leq \theta^{*}$ and $v_{0}(\theta)=\theta^{*} F(K)$ if $\theta>\theta^{*}$. We interpret $\theta^{*} F(K)$ as the face value of the project's debt. In the event that the realized value of the project exceeds the face value of the debt, the debt is paid. In the event that the realized value of the project is less than the face value of the debt, the project is bankrupt, monitored, and all remaining value is paid to the debt holders. If one assumes that the debt holders bear the cost of monitoring, the market value of the project's debt is given by

$$
D=\left[\int_{0}^{\theta^{*}} \theta p(\theta) d \theta+\left(1-P\left(\theta^{*}\right)\right) \theta^{*}-P\left(\theta^{*}\right) \gamma\right] F(K) .
$$

Note that under the assumption that the debt holders bear the cost of monitoring, the value of $D$ can be negative since it is net of the cost of monitoring. Alternatively, one may assume that the outside investors jointly contribute resources $\gamma F(K)$ in addition to uncontingent 
payments $K$ and $\bar{w}$ in the first sub-period. Under this alternative assumption, the market value of the debt is given by

$$
D=\left[\int_{0}^{\theta^{*}} \theta p(\theta) d \theta+\left(1-P\left(\theta^{*}\right)\right) \theta^{*}+\left(1-P\left(\theta^{*}\right)\right) \gamma\right] F(K)
$$

which is always positive. This alternative assumption can also rationalize commitment to deterministic monitoring since the proceeds from monitoring are nonnegative even if $\theta=0$, and are positive for $\theta>0$.

The residual payout from the project is associated with the payments to the outside equity holders. In the event of bankruptcy $\left(\theta \leq \theta^{*}\right)$, the outside equity holders receive no payment. In the event that $\theta>\theta^{*}$ and $\theta \leq \bar{\theta}$, the outside equity holders receive payment $\left(\theta-\theta^{*}\right) F(K)$, which is the realized value of the project less the payment to the debt holders. (Recall that the base portion of the manager's pay, $\bar{w}$, was set aside in advance). In the event that $\theta>\bar{\theta}$, the outside equity holders receive $\left(\theta-\theta^{*}-\tau(\theta-\bar{\theta})\right) F(K)$ which is equal to the realized value of the project less the payments to the debt holders and the payments to the manager on the performance portion of his compensation.

Note that in our model, the performance component of the manager's pay resembles an option on the value of the firm with strike price $\bar{\theta} F(K)$, or equivalently an option on the value of the equity of the firm with strike price $\left(\bar{\theta}-\theta^{*}\right) F(K)$. This result that the performance component of the manager's pay resembles an option on the firm is driven by our assumption that the agency friction applies to the entire value of the firm - that is, by our assumption that the manager can spend up to fraction $\tau$ of all of the undisbursed output of the firm at the end of the second sub-period. 
More generally, the measure of firm performance upon which the manager's performance pay is based is determined by the extent of the agency friction. To see this, consider a variant of our model in which firm output had two components: current cash flow $\theta f(K)$ and undepreciated capital $(1-\delta) K$. Assume that the manager is able to spend up to fraction $\tau$ of undisbursed cash flow on perquisites, but that he cannot divert undepreciated capital for his own use. In this variant of the model, the constraint (2) on payments to the manager would be modified to read

$$
\begin{aligned}
& u(x(\hat{\theta}, \theta)) \geq u\left(\tau\left(\theta f(K)-v_{0}(\hat{\theta})\right)\right) \text { for all } \hat{\theta} \notin M, \text { and } \\
& u(x(\hat{\theta}, \theta)) \geq u\left(\tau\left(\theta f(K)-v_{1}(\hat{\theta}, \theta)\right)\right) \text { for all } \hat{\theta} \in M,
\end{aligned}
$$

and the limited liability constraint (1) would be modified to read

$$
v_{0}(\hat{\theta}) \leq \hat{\theta} f(K)+(1-\delta) K, v_{1}(\hat{\theta}, \theta) \leq \theta f(K)+(1-\delta) K, \text { and } x(\hat{\theta}, \theta) \geq 0 .
$$

It is straightforward to show that the optimal contract in this variant of the model would break down into four payments as before, except in this case, the performance pay to the manager would be based on cash flow $\theta f(K)$ and not on the value of the firm (which includes the value of undepreciated capital). It is also straightforward in this variant of the model to interpret the payments $v$ backed by undepreciated capital $(1-\delta) K$ as payments to collateralized debt. It is worth noting, however, that our model does not have predictions regarding the optimal mix of collateralized and uncollateralized debt. 


\section{Capital Structure, Production and Monitoring}

The standard result due to Modigliani and Miller (19??) is that in a frictionless world, the capital structure of a firm has no impact on its efficient production plan. Here we have assumed specific frictions that determine the optimal capital structure of the firm. In this section, we discuss the impact of these frictions of the firm's efficient production plan as characterized in Proposition 3 below. In particular, we show that, under the optimal production plan, there is a wedge between the expected marginal product of capital within the firm and the opportunity cost of capital. Our main result is that the magnitude of this wedge can be measured in terms of elements of the firm's capital structure and its executive compensation.

We refer to an economy in which the monitoring cost $\gamma=0$ as a frictionless environment. In such an environment, the optimal contract specifies that the outside investors

monitor the output of the project in the second sub-period for all values of $\hat{\theta}$ and pay the manager constant compensation $\bar{w}$ independent of the realized value of $\theta$. In this frictionless environment, the efficient capital stock satisfies $F^{\prime}(K)=r$. In contrast, with financial frictions, there is a wedge between the marginal product of capital and its rental rate. We characterize this wedge in proposition 3.

Proposition 3. Assume that the support of $\theta$ in unbounded above. Then, under the optimal contract, $F^{\prime}(K)>r$.

Proof: The first order-condition of (10) with respect to $K$ is given by

$$
\left[\int\left\{\theta-\delta(\theta) u^{\prime}\left(\tau\left(\theta-\theta^{*}\right) F(K)\right) \tau\left(\theta-\theta^{*}\right)\right\} p(\theta) d \theta-\gamma P\left(\theta^{*}\right)\right] F^{\prime}(K)=r
$$


From (11) and (12), we have that

$$
\delta(\theta)=\frac{1}{u^{\prime}(w(\theta))}-\frac{1}{u^{\prime}(\bar{w})} .
$$

With this result and the assumption that the expectation of $\theta$ is 1 , this first order condition for capital simplifies to

$$
\left\{1-\gamma P\left(\theta^{*}\right)-\int_{\bar{\theta}}^{\infty}\left[1-\frac{u^{\prime}\left[\tau\left(\theta-\theta^{*}\right) F(K)\right]}{u^{\prime}(\bar{w})}\right] \tau\left(\theta-\theta^{*}\right) p(\theta) d \theta\right\} F^{\prime}(K)=r .
$$

Note $\bar{w}$ is finite as long as the manager's reservation utility is finite. Hence the assumption that the support of $\theta$ is unbounded above implies that $P(\bar{\theta})<1$. Thus, since

$$
0<1-\frac{u^{\prime}\left[\tau\left(\theta-\theta^{*}\right) F(K)\right]}{u^{\prime}(\bar{w})}<1 \forall \theta>\bar{\theta}
$$

we have that

$$
1-\gamma P\left(\theta^{*}\right)-\int_{\bar{\theta}}^{\infty}\left[1-\frac{u^{\prime}\left[\tau\left(\theta-\theta^{*}\right) F(K)\right]}{u^{\prime}(\bar{w})}\right] \tau\left(\theta-\theta^{*}\right) p(\theta) d \theta<1 .
$$

Hence, $F^{\prime}(K)>r$. Q.E.D.

Note that the assumption that the support of $\theta$ is unbounded above is sufficient to ensure that $F^{\prime}(K)>r$, but it is not necessary. What is necessary is that either $P\left(\theta^{*}\right)>0$ or $P(\bar{\theta})<1$, so that either there is monitoring or there is not perfect risk sharing.

From (14), one can see that there are two parts to this wedge between $F^{\prime}(K)$ and $r$. The first part is the expected loss due to monitoring given by $\gamma P\left(\theta^{*}\right)$. This loss is a cost of 
debt since the monitoring that debt requires in the event of bankruptcy results in a loss of output. The second part of the wedge is the loss due to inefficient risk-sharing between the outside investors and the manager that arises as a result of the performance component of the manager's compensation. Specifically, this is the loss due to the fact that the risk averse manager places a lower valuation on the state contingent component of his compensation than the outside investors do, and this loss is represented by the term

$$
\int_{\bar{\theta}}^{\infty}\left[1-\frac{u^{\prime}\left[\tau\left(\theta-\theta^{*}\right) F(K)\right]}{u^{\prime}(\bar{w})}\right] \tau\left(\theta-\theta^{*}\right) p(\theta) d \theta .
$$

To interpret this term, observe that the outside investors value the manager's option at $\int_{\bar{\theta}}^{\infty} \tau\left(\theta-\theta^{*}\right) p(\theta) d \theta$. In contrast, the payment of $\tau\left(\theta-\theta^{*}\right)$ to the manager in the event that productivity $\theta>\bar{\theta}$ is realized raises the manager's utility by $u^{\prime}\left[\tau\left(\theta-\theta^{*}\right) F(K)\right] \tau\left(\theta-\theta^{*}\right)$ and hence relaxes the promise keeping constraint by an amount that is worth only

$$
\frac{u^{\prime}\left[\tau\left(\theta-\theta^{*}\right) F(K)\right]}{u^{\prime}(\bar{w})} \tau\left(\theta-\theta^{*}\right)
$$

to the outside investors.

Log Preference Example: If we assume that $u(c)=\log (c)$, then the first order condition for capital (14) reduces to

$$
\left\{1-\gamma P\left(\theta^{*}\right)-\int_{\bar{\theta}}^{\infty} \tau(\theta-\bar{\theta}) p(\theta) d \theta\right\} F^{\prime}(K)=r .
$$

Hence, in this case the wedge between the marginal product of capital and the rental rate on capital is given by one minus the sum of the fraction of expected output $(F(K))$ devoted to 
the monitoring cost and the fraction of expected output paid to the manager as the option portion of his compensation. Thus, in this example, it is a simple matter to link our model's implications for the impact of financial frictions on efficient production plans to observables.

We turn next to the determination of the optimal extent of monitoring. The first order-condition of $(10)$ with respect to $\theta^{*}$ can be written as follows once we substitute for $\delta(\theta)$ as we did in the capital condition (14),

$$
\tau \int_{\bar{\theta}}^{\infty}\left(1-\frac{u^{\prime}\left[\tau\left(\theta-\theta^{*}\right) F(K)\right]}{u^{\prime}(\bar{w})}\right) p(\theta) d \theta=\gamma p\left(\theta^{*}\right) F(K)
$$

This condition implies that under the efficient contract, $\theta^{*}$ is determined by a trade-off between the marginal cost of monitoring as captured by the right hand side of the above expression, and the marginal impact of monitoring on the cost of distorting the manager's consumption, as captured by the left hand side of the above expression.

\section{The Dynamic Contracting Problem}

We now consider the optimal contracting problem in a dynamic extension of our one period model. In this section we show that the optimal dynamic contract is quite similar to the optimal static contract in that it can be broken down into four payments: base pay and performance pay for the manager, debt, and outside equity. We then show that the manager's pay is non-decreasing over time. In this section, we keep our problem simple by assuming that all managers are equally productive in running the firm. In a later section, we introduce the possibility that the incumbent manager in the firm may, at random, become unproductive at running the firm. With this further extension of the model, we show how 
a "golden parachute" forms part of the optimal package of executive compensation. In the next section, we discuss several issues concerning the interpretation of an optimal contract in this dynamic setting as a theory of the capital structure of the firm.

The extension of our one period model to a dynamic setting is as follows. Each period consists of three sub-periods as described above. In the first sub-period, the outside investors hire a manager to run the project and put forward capital. In the second sub-period, the current productivity shock $\theta$, and hence current output $y=\theta F(K)$, is realized, and these values are observed only by the manager. The manager makes some payment to the outside investors in this second sub-period. At the end of the second sub-period, the manager has the option of investing up to fraction $\tau$ of the remaining output of the firm into perks that he consumes and otherwise he reinvests the remaining output of the firm at gross rate of return one. In the third sub-period, the realized value of the shock $\theta$ becomes public information, as well as the manager's division of the firm's output between perks and productive reinvestment. The manager is paid in this third sub-period. This production process is then repeated in subsequent periods. We interpret this cycle of information about production as corresponding to an accounting cycle or a capital budgeting cycle within the firm.

We assume that all managers not running a project have an outside opportunity to enjoy consumption $\bar{c}$ each period. Corresponding to this consumption flow is a reservation expected discounted utility level $U_{0}$. Individual rationality requires that new managers can expect utility of at least $U_{0}$ under a contract and that incumbent managers can expect a utility of at least $U_{0}$ in the continuation of any contract.

We present a recursive characterization of the optimal dynamic contract. Accordingly, we assume that the incumbent manager is indexed by a utility level $U$ promised him from this 
period forward under the contract the previous period. This utility level is a contractual state variable carried over from the previous period and hence is determined before the realization of the productivity shock $\theta$. We let $V(U)$ denote the expected discounted value of payments to outside investors given utility promise of $U$ to the incumbent manager.

A dynamic contract has the following elements. Given the utility $U$ promised to the incumbent manager as a state variable, the contract specifies a monitoring region $M(U)$ with indicator function $m(\hat{\theta} ; U)$ indicating the monitoring decision as a function of the manager's report, payments from the manager to the outside investors in the second subperiod $v_{0}(\hat{\theta} ; U)$ if there is no monitoring and $v_{1}(\hat{\theta}, \theta ; U)$ if there is monitoring, and payments from the outside investors to the manager in the third subperiod $x(\hat{\theta}, \theta ; U)$. The recursive representation of the contract also specifies continuation utilities $Z(\hat{\theta}, \theta ; U)$ for the incumbent manager. In what follows, we suppress reference to $U$ where there is no risk of confusion.

These terms of the contract are chosen subject to the limited liability constraints (1). Since the incumbent manager can always quit and take his outside opportunity in the next period, we have an individual rationality constraint

$$
Z(\hat{\theta}, \theta) \geq U_{0} \text { for all } \hat{\theta}, \theta
$$

We require that the contract deliver the promised utility $U$ to the incumbent manager

$$
\int[u(x(\theta, \theta))+\beta Z(\theta, \theta)] p(\theta) d \theta=U .
$$

The incumbent manager must be induced to truthfully report $\theta$ in the second sub-period. 
Hence we have incentive constraints, for all $\theta$ and $\hat{\theta} \notin M$ such that $\hat{\theta}$ is feasible in that $\theta \geq v_{0}(\hat{\theta}) / F(K)$

$$
u(x(\theta, \theta))+\beta Z(\theta, \theta) \geq u(x(\hat{\theta}, \theta))+\beta Z(\hat{\theta}, \theta) .
$$

Finally, there is a dynamic analog to the constraint (2) arising from the assumption that the manager can spend fraction $\tau$ of whatever resources are left in the project at the end of the second sub-period on perks that he enjoys. This constraint is given by

$$
\begin{aligned}
& u(x(\hat{\theta}, \theta))+\beta Z(\hat{\theta}, \theta) \geq u\left(\tau\left(\theta F(K)-v_{1}(\hat{\theta}, \theta)\right)\right)+\beta U_{0} \text { if } \hat{\theta} \in M \\
& u(x(\hat{\theta}, \theta))+\beta Z(\hat{\theta}, \theta) \geq u\left(\tau\left(\theta F(K)-v_{0}(\hat{\theta})\right)\right)+\beta U_{0} \text { if } \hat{\theta} \notin M
\end{aligned}
$$

for all $\theta$ and for all $\hat{\theta} \notin M$ such that $v_{0}(\hat{\theta}) \leq \theta F(K)$. Here we have used the requirement that the manager's continuation utility cannot be driven down below $U_{0}$ in the left-hand side of (20) to compute the manager's utility in the event that he invests in perks and then is fired as a consequence.

The terms of the dynamic contract are chosen to maximize the expected discounted payments to the outside investors. This problem is to choose $K, m(\hat{\theta}), v_{0}(\hat{\theta}), v_{1}(\hat{\theta}, \theta), x(\hat{\theta}, \theta)$, and $Z(\hat{\theta}, \theta)$ to maximize

$$
V(U)=\max \int\left\{(\theta-\gamma m(\theta)) F(K)-x(\theta, \theta)+\frac{1}{R} V(Z(\theta, \theta))\right\} p(\theta) d \theta-r K
$$

subject to the constraints (1), (17), (18), (19), and (20). 
In the remainder of this section, we characterize elements of an efficient dynamic contract. In proposition 4 , we show that the optimal dynamic contract is similar to the optimal static contract in that the monitoring set is an interval from 0 to $\theta^{*}$, and payments in the second sub-period are given by $v_{1}(\hat{\theta}, \theta)=\theta F(K)$ if there is monitoring and $v_{0}(\hat{\theta})=$ $\theta^{*} F(K)$ where $\theta^{*} \equiv \inf \{\hat{\theta} \mid \hat{\theta} \notin M\}$ if there is no monitoring. The line of argument here is similar to that in proposition 1.

In proposition 5, we discuss the manager's pay and retention. We show that the manager's pay consists again of a constant base pay level denoted $\bar{w}$ and then an increasing portion of pay if a sufficiently high realization of $\theta$ occurs. The line of argument on compensation is similar to that for Proposition 2. We also show that, under the optimal dynamic contract, if $\beta \geq 1 / R$, then the pay to the incumbent manager is non-decreasing over time.

Proposition 4. There is an efficient contract with the following properties: $(i) v_{1}(\hat{\theta}, \theta)=$ $\theta F(K)$ for all $\hat{\theta} \in M$ and $v_{0}(\hat{\theta})=\theta^{*} F(K)$, where $\theta^{*} \equiv \inf \{\hat{\theta} \mid \hat{\theta} \notin M\},(i i) M$ is an interval ranging from 0 to $\theta^{*}$, and (iii) $x(\hat{\theta}, \theta)=0$ and $Z(\hat{\theta}, \theta)=U_{0}$ for $\hat{\theta} \neq \theta$ and $\hat{\theta} \in M$ and $x(\hat{\theta}, \theta)=\tau\left(\theta-\theta^{*}\right) F(K)$ and $Z(\hat{\theta}, \theta)=U_{0}$ for $\hat{\theta} \neq \theta$ and $\hat{\theta} \notin M$.

Proof: The proof here is quite similar to the proof of proposition 1. For all $\hat{\theta} \in M$, setting $v_{1}(\hat{\theta}, \theta)=\theta F(K)$ relaxes the constraint (20) as much as possible and has no effect on the objective (21) nor on any other constraint. Again define $v_{0}^{*}=\inf \left\{v_{0}(\hat{\theta}) \mid \hat{\theta} \notin M\right\}$ and $\theta^{*}=$ $\inf \{\theta \mid \theta \notin M\}$. Observe that to relax the constraint (19) as much as possible, the manager's utility following a misreporting of $\hat{\theta} \neq \theta$ should be set as low as possible. Given (1), (17), 
and $(20)$, this gives $x(\hat{\theta}, \theta)=0, Z(\hat{\theta}, \theta)=U_{0}$ for $\hat{\theta} \neq \theta$ and $\hat{\theta} \in M$, and

$$
u(x(\hat{\theta}, \theta))+\beta Z(\hat{\theta}, \theta)=u\left(\tau\left(\theta F(K)-v_{0}^{*}\right)\right)+\beta U_{0}
$$

for $\hat{\theta} \notin M$, and $\theta \geq v_{0}^{*} / F(K)$. Again, holding fixed the monitoring set, setting $v_{0}^{*}$ as high as is feasible relaxes this constraint as much as possible. Since feasibility requires that $\theta^{*} F(K) \geq$ $v_{0}^{*}$, this gives us that under an optimal contract, $v_{0}^{*}=\theta^{*} F(K)$. That $M$ is an interval follows from the argument that including some $\theta>\theta^{*}$ in the monitoring set does nothing to relax (22) and does require resources for monitoring. That $x(\hat{\theta}, \theta)=\tau\left(\theta-\theta^{*}\right) F(K)$ for $\hat{\theta} \neq \theta$, $\hat{\theta} \notin M$ follows from the result that $v_{0}^{*}=\theta^{*} F(K)$. Q.E.D.

With this proposition, we can write our optimal contracting problem more simply as one of choosing capital $K$, the upper support of the monitoring set $\theta^{*}$, current managerial pay $w(\theta)=x(\theta, \theta)$, and continuation values $W(\theta)=Z(\theta, \theta)$ to maximize the payoff to the outside investors

$$
V(U)=\max \int\left\{\theta F(K)-w(\theta)+\frac{1}{R} V(W(\theta))\right\} p(\theta) d \theta-\gamma P\left(\theta^{*}\right)-r K
$$

subject to the promise-keeping constraint

$$
\int[u(w(\theta))+\beta W(\theta)] p(\theta) d \theta=U
$$

the dynamic no-perks constraint

$$
u(w(\theta))+\beta W(\theta) \geq u\left(\tau\left(\theta-\theta^{*}\right) F(K)\right)+\beta U_{0}
$$


As in the static case, we can derive several results regarding the characteristics of managerial compensation from the first order conditions of this problem. These characteristic include that managerial pay consists of base pay plus a performance based component and that pay for the incumbent manager is non-decreasing over time.

Proposition 5. There is an optimal contract under which there is a cutoff $\bar{\theta}$ together with a level of base pay $\bar{w}$ for the manager such that $w(\theta)=\bar{w}$ and the continuation values $W(\theta)$ are also constant at $\bar{W}$ for $\theta \leq \bar{\theta}$. Both $w(\theta)$ and $W(\theta)$ are increasing for $\theta>\bar{\theta}$. If $\beta R \geq 1$, then managerial pay $w(\theta) F(K)$ is non-decreasing over time.

Proof: The proof is quite similar to that of proposition 2 and follows from the first order conditions of the optimal contracting problem. Let $\lambda$ be the Lagrangian multiplier on the constraint (18) and $\rho \delta(\theta) p(\theta)$ the Lagrangian multipliers on the constraints (25). The first order conditions of this problem with respect to $w(\theta)$ and $W(\theta)$ are

$$
1=(\lambda+\delta(\theta)) u^{\prime}(w(\theta)),
$$

and

$$
-\frac{1}{R} V^{\prime}(W(\theta))=\beta(\lambda+\delta(\theta)) .
$$

These first order condition imply that $w(\theta)$ and $W(\theta)$ are constant unless the constraint (25) binds. Note that since $u\left(\tau\left(\theta-\theta^{*}\right) F(K)\right)+\beta U_{0}$ is increasing in $\theta$, there is a cutoff $\bar{\theta}$ such that this constraint does not bind for $\theta \leq \bar{\theta}$ and binds for $\theta>\bar{\theta}$. When the constraint (25) 
binds, the optimal choices of $w(\theta)$ and $W(\theta)$ satisfy

$$
1=-\frac{1}{\beta R} V^{\prime}(W(\theta)) u^{\prime}(w(\theta))
$$

and (25) as an equality. Hence, $w(\theta)$ and $W(\theta)$ are both increasing in $\theta$ when this constraint binds. To prove that if $\beta R=1$, then $w(\theta)$ is non-decreasing over time, we use the envelope condition $-V^{\prime}(U)=\lambda$.Plugging this into the first order conditions for $w(\theta)$ and $W(\theta)$ and using $\beta R=1$ gives

$$
u^{\prime}(w(\theta)) / u^{\prime}\left(\bar{w}^{\prime}\right)=\beta R \geq 1
$$

where $\bar{w}^{\prime}$ and $F\left(K^{\prime}\right)$ are next period's values of these variables. Hence $\bar{w}^{\prime} \geq w(\theta)$, which gives our result.

Note that this proposition implies that performance bonuses paid in one period are incorporated into the manager's base pay in future periods.

Remark 1. Because there is complete resolution of uncertainty at the end of each period, it is straightforward to extend the model to allow for persistence in the idiosyncratic productivity shock.

To be concrete, assume that the production shock follows a Markov process, and therefore the c.d.f. $P\left(\theta ; \theta_{-1}\right)$ and p.d.f. $p\left(\theta ; \theta_{-1}\right)$ are conditional on the prior periods shock $\theta_{-1}$. This time dependence in the shock would mean that the return to the outside investors and the elements of the efficient contract would be functions of both the ex-ante promised utility $U$ and the prior period's shock $\theta_{-1}$. 


\section{Capital structure in the dynamic model}

In this section, we discuss two issues that arise in interpreting an efficient contract in our model as a theory of the capital structure of the firm and the compensation of the firm's manager. The first of these issues concerns our model's implications for the optimal debt-equity ratio of the firm. We show here that while our model does have implications for the payments to debt and equity holders, it does not pin down the debt-equity ratio of the firm. The second of these issues concerns the interpretation of the monitoring of the firm by outside investors as bankruptcy.

Our dynamic model delivers a theory of the division of the gross payments out of an ongoing firm between holders of the firm's debt, outside equity, and the firm's manager. This division of gross payments is not sufficient, however, to pin down the relative value of the firm's debt and equity. This is because our model does not pin down whether it is the debt holders or the outside equity holders who pay for the investments $K$ in future periods. This issue is not new to our model and can arise in any financial contract in which there are multiple flows out of the firm.

We illustrate this problem with the following simple example. Imagine that an entrepreneur has created a project that can be operated for 2 periods in which an investment of 1 at the beginning of each period produces an output of 2 at the end of each period. Assume that this entrepreneur sells this project to outside investors after having made the initial investment at the beginning of period 1 and that there is no discounting, so that the total value of this project is equal to 3 units of output ( 2 units of output in period 1 plus two more units in period 2 less 1 unit of investment in period 2). Hence, it is clear in a competitive capital market, the outside investors must pay the entrepreneur 3 units of output at the beginning 
of period 1 to purchase this project. What is to be determined is the division of this value between outside investors who hold debt and outside investors who hold equity. Imagine further that a theory such has ours has yielded the implication that, each period, the gross output of 2 is divided equally between debt and equity holders, so 1 unit is paid to the debt holders and 1 unit is paid to the equity holders. As the following examples make clear, the division of the value of this firm between debt and equity is not pinned down under these assumptions, despite the fact that the division of the gross payments to the outside investors is pinned down.

To see this, assume first that the firm is financed with a combination of short-term debt and equity. In particular, assume that short-term debt holders lend one unit at the beginning of each period and are repaid that one unit at the end of each period. In period 1, the equity holders pay 2 units to the entrepreneur to purchase the project and the remainder of the purchase is financed with the first issuance of 1 unit of short-term debt. The equity holders in this case receive a dividend of one unit each period in exchange for their investment while the investment of 1 unit required at the beginning of the second period is financed by a second issuance of short-term debt at the beginning of period 2. Under these assumptions, in the first period, after the initial investment of 1 unit has been made, the value of the debt is 1 unit and the value of the equity is 2 units.

Next assume that the investment of one unit in the firm at the beginning of the second period is financed by the outside equity holders (through retained earnings) while the debt is long-term debt. In this case, to purchase this project, one group of outside investors puts forward 2 units of output in exchange for a long-term debt claim that pays 1 unit at the end of each of the two periods while another group of outside investors puts forward 1 unit 
of output in exchange for an equity stake that pays no dividend in the first period and a dividend of 1 unit at the end of the second period. The three units of output raised in this way are used to purchase the project from the entrepreneur. Under this financing scheme, the firm's debt is worth 2 units and the firm's equity is worth 1 unit.

As this simple example makes clear, under different assumptions about the division of responsibility for ongoing investments in the firm, one obtains different implications for the debt-equity ratio of the firm. We conjecture that this issue will arise in any well-specified "trade-off" theory of optimal capital structure.

In interpreting our efficient contract as a theory of capital structure, we associate monitoring with bankruptcy. Monitoring in our model occurs whenever the current gross output of the firm fall below a threshold $\theta^{*} F(K)$ determined by the optimal contract. In our one-period version of the model, in the event that $\theta \leq \theta^{*}$, monitoring occurred, all of the remaining value of the firm was paid to debt-holders and the outside equity holders received nothing. In this sense, in the one-period model, monitoring corresponds to a stylized notion of bankruptcy. In a multi-period version of our model, the division of the value of the firm between debt and equity holders in the event of monitoring is not so stark. In the event that $\theta \leq \theta^{*}$, monitoring occurs, but the firm still has a value to the outside investors as an ongoing concern (denoted by the continuation value $V(W(\theta))$ ). In the event that this continuation value exceeds the face value of the debt, then the equity holders emerge from this episode of bankruptcy with shares that still have positive value. In this sense, monitoring in the dynamic model does not necessarily correspond to the liquidation of the firm. Of course, the same is true of bankruptcy in the data. 


\section{Retention and Golden Parachutes}

We now extend our dynamic model to include a decision whether to retain the manager. This decision is contingent on the realization of an observable shock that affects the productivity of the incumbent manager in running the firm. Outside investors have an incentive to retain incumbent managers with high productivity and replace those with low productivity. We show that a golden parachute type payment to an incumbent manager who becomes unproductive and is fired is part of the optimal compensation scheme.

To extend the model, we assume that each period, the incumbent manager who has been running the project experiences a shock $\eta \in\{0,1\}$ at the beginning of the period to his productivity with this project, so that the project's output is given by $\eta \theta F(K)$. This shock $\eta$ is observable to all parties. This shock follows a Markov process in which $\eta=0$ is an absorbing state and the probability that $\eta=1$ in the current period given that $\eta=1$ in the previous period is given by $\rho$. As we show below, along the equilibrium path, the outside investors choose to continue with the incumbent manager if $\eta=1$ and they hire a new manager if $\eta=0$. Hence, in what follows we suppress reference to $\eta$ where there is no risk of confusion.

With this alteration to our model, we need to include additional terms in the contract between the outside investors and the manager. In particular, we need to include a payment from the outside investors make to the incumbent manager in the event that he is not retained as well as notation for the cost to the outside investors of hiring a new manager. Let $\tilde{V}\left(w^{F}\right)$ denote the indirect lifetime utility of the incumbent manager in the event that he is not

retained and paid $w^{F}$. We assume that $\tilde{V}(0) \leq U_{0}$, that is that an incumbent manager who has been fired with no severance pay gets no more than the reservation utility of an 
unemployed manager.

Since our results characterizing an efficient contract in proposition 4 carry over here, we can express the problem of choosing the optimal contract as one of choosing contract terms $w(\theta), \theta^{*}, K, W(\theta) \geq U_{0}$ together with the payment that a manager receives if he is not retained $w^{F}$ so as to maximize the objective

$$
V(U)=\max _{w^{F}, U^{R}}\left(V_{0}-w^{F}\right)(1-\rho)+\rho V^{R}\left(U^{R}\right)
$$

subject to the promise-keeping constraint

$$
\rho U^{R}+(1-\rho) \tilde{V}\left(w^{F}\right)=U
$$

Here $V^{R}$ is notation for the value of retaining the incumbent manager when that manager receives continuation utility $U^{R}$ conditional on being retained. The function $V^{R}\left(U^{R}\right)$ is defined by

$$
V^{R}\left(U^{R}\right)=\max _{w(\cdot), W(\cdot), \theta^{*}, K} \int\left\{\theta F(K)-w(\theta)+\frac{1}{R} V(W(\theta))\right\} p(\theta) d \theta-\gamma F(K) P\left(\theta^{*}\right)-r K
$$

subject to

$$
\int[u(w(\theta))+\beta W(\theta)] p(\theta) d \theta=U^{R}
$$


and the dynamic no-perks constraint

$$
u(w(\theta))+\beta W(\theta) \geq u\left(\tau\left(\theta-\theta^{*}\right) F(K)\right)+\beta U_{0} .
$$

The term $V_{0}$ denotes the value to the outside investors of hiring a new manager (with $\eta=1$ and $\left.U=U_{0}\right)$ and is defined as the solution to the problem of choosing $w_{0}(\theta), \theta_{0}^{*}, K_{0}, W_{0}(\theta) \geq$ $U_{0}$ to maximize

$$
V_{0}=\int\left\{\theta F\left(K_{0}\right)-w_{0}(\theta)+\frac{1}{R} V\left(W_{0}(\theta)\right)\right\} p(\theta) d \theta-\gamma F\left(K_{0}\right) P\left(\theta_{0}^{*}\right)-r K_{0}
$$

subject to

$$
\int\left[u\left(w_{0}(\theta)\right)+\beta W_{0}(\theta)\right] p(\theta) d \theta=U_{0}
$$

and the constraint (29).

In the next proposition, we establish the optimality of a golden parachute payment to incumbent managers who have become unproductive.

Proposition 6. In the event that $\eta=0$, then the manager's pay satisfies $\tilde{V}^{\prime}\left(w_{0}\right)=u^{\prime}(\bar{w})$.

Proof: Let $\lambda$ be the Lagrangian multiplier on the constraint (26). From the first order conditions for $w^{F}$ and $U^{R}$ we have

$$
1=-V^{R \prime}\left(U^{R}\right) \tilde{V}^{\prime}\left(w^{F}\right)
$$


The envelope condition from the problem defining $V^{R}\left(U^{R}\right)$ we get that $V^{R^{\prime}}\left(U^{R}\right)=-1 / u^{\prime}(\bar{w})$, hence

$$
u^{\prime}(\bar{w})=\tilde{V}^{\prime}\left(w^{F}\right),
$$

where $\bar{w}$ is the base pay to the manager if he is retained.

This proposition implies that the optimal golden parachute payment to an incumbent manager who has been unproductive should be large enough to allow him to maintain the living standard that was guaranteed in his base pay. The optimal size of this golden parachute payment will be larger, then, the more limited the outside options of the manager in the event that he is not retained.

\section{Comparative Statics}

We now consider how the terms of the optimal contract for financing the firm depend on the parameters $\tau, U_{0}$, and $\gamma$ governing the severity of the agency problem and the costs of monitoring the output of the firm. We focus on the one-period contracting problem. In general, these comparative statics depend on the parameters of the manger's utility, the distribution of shocks $\theta$, and the production function $F$. We present analytic results here under the assumption that the manager's utility is CRRA, the distribution of shocks $\theta$ is uniform, and the optimal choice of capital $K$ is fixed. With $K$ fixed, the contract terms that vary are base pay $\bar{w}$, the set of states $\theta<\theta^{*}$ for which monitoring occurs, and the set of states 
$\theta>\bar{\theta}$ for which the manager receives a performance bonus. These contract terms maximize

$$
\max _{\bar{w}, \bar{\theta}, \theta^{*}} F(K) \int_{0}^{\infty} \theta p(\theta) d \theta-\bar{w} P(\bar{\theta})-\tau F(K) \int_{\bar{\theta}}^{\infty}\left(\theta-\theta^{*}\right) p(\theta) d \theta-\gamma P\left(\theta^{*}\right) F(K)-r K
$$

subject to the constraints that

$$
u(\bar{w}) P(\bar{\theta})+\int_{\bar{\theta}}^{\infty} u\left(\tau\left(\theta-\theta^{*}\right) F(K)\right) p(\theta) d \theta=U_{0}
$$

and

$$
\bar{w}=\tau\left(\bar{\theta}-\theta^{*}\right) F(K)
$$

Proposition 7. Assume that $u(c)=\left(c^{1-\phi}-1\right) /(1-\phi), \theta$ is uniformly distributed, and $F(K)=\min \{K, 1\}$. If $\bar{w}$ and $\theta^{*}$ are an interior solution of the problem (32) and the optimal choice of $K$ is fixed at 1 , then

1. monitoring $\theta^{*}$ and the bonus cutoff $\bar{\theta}$ are increasing in the perks parameter $\tau$. The effect on base pay $\bar{w}$ is ambiguous.

2. base pay $\bar{w}$ is increasing and monitoring $\theta^{*}$ and the bonus cutoff $\bar{\theta}$ are decreasing in the reservation utility $U_{0}$

3. base pay $\bar{w}$ is increasing and monitoring $\theta^{*}$ and the bonus cutoff $\bar{\theta}$ are increasing in the monitoring cost $\gamma$

Proof: We proof this proposition by differentiating the first order conditions determining the optimal choice of contract terms. We use (34) to substitute out for $\bar{w}$ in (32) and 
derive the following first-order conditions determining the optimal choice of $\theta^{*}$ and $\bar{\theta}$

$$
\begin{aligned}
& \int_{\bar{\theta}}^{\infty}\left(1-\frac{u^{\prime}\left[\tau\left(\theta-\theta^{*}\right) F(K)\right]}{u^{\prime}\left[\tau\left(\bar{\theta}-\theta^{*}\right) F(K)\right]}\right) p(\theta) d \theta=\frac{\gamma}{\tau} p\left(\theta^{*}\right) F(K) . \\
& u\left(\tau\left(\bar{\theta}-\theta^{*}\right) F(K)\right) P(\bar{\theta})+\int_{\bar{\theta}}^{\infty} u\left(\tau\left(\theta-\theta^{*}\right) F(K)\right) p(\theta) d \theta=u\left(c_{0}\right)
\end{aligned}
$$

where $\bar{c}$ is defined to solve $u\left(c_{0}\right)=U_{0}$. Using the homogeneity of the CRRA utility function, these equations simplify to

$$
\begin{aligned}
& \int_{\bar{\theta}}^{\infty}\left(1-\frac{u^{\prime}\left(\theta-\theta^{*}\right)}{u^{\prime}\left(\bar{\theta}-\theta^{*}\right)}\right) p(\theta) d \theta-\frac{\gamma}{\tau} p\left(\theta^{*}\right) F(K)=0 \\
& u\left(\bar{\theta}-\theta^{*}\right) P(\bar{\theta})+\int_{\bar{\theta}}^{\infty} u\left(\theta-\theta^{*}\right) p(\theta) d \theta=u\left(\frac{c_{0}}{\tau F(K)}\right) .
\end{aligned}
$$

Differentiating these equations with respect to $\bar{\theta}, \theta^{*}$ and the parameters $\tau, c_{0}$, and $\gamma$ gives

$$
\begin{aligned}
& {\left[\frac{u^{\prime \prime}\left(\bar{\theta}-\theta^{*}\right)}{u^{\prime}\left(\bar{\theta}-\theta^{*}\right)} \int_{\bar{\theta}}^{\infty} \frac{u^{\prime}\left(\theta-\theta^{*}\right)}{u^{\prime}\left(\bar{\theta}-\theta^{*}\right)} p(\theta) d \theta\right] d \bar{\theta}+} \\
& {\left[\int_{\bar{\theta}}^{\infty} \frac{u^{\prime \prime}\left(\theta-\theta^{*}\right)}{u^{\prime}\left(\bar{\theta}-\theta^{*}\right)}-\frac{u^{\prime \prime}\left(\bar{\theta}-\theta^{*}\right)}{u^{\prime}\left(\bar{\theta}-\theta^{*}\right)} \frac{u^{\prime}\left(\theta-\theta^{*}\right)}{u^{\prime}\left(\bar{\theta}-\theta^{*}\right)} p(\theta) d \theta-\frac{\gamma}{\tau} p^{\prime}\left(\theta^{*}\right) F(K)\right] d \theta^{*}} \\
& =\frac{1}{\tau} p\left(\theta^{*}\right) F(K) d \gamma-\frac{\gamma}{\tau^{2}} p\left(\theta^{*}\right) F(K) d \tau
\end{aligned}
$$

$$
\begin{aligned}
& u^{\prime}\left(\bar{\theta}-\theta^{*}\right) P(\bar{\theta}) d \bar{\theta}-\left[u^{\prime}\left(\bar{\theta}-\theta^{*}\right) P(\bar{\theta})+\int_{\bar{\theta}}^{\infty} u^{\prime}\left(\theta-\theta^{*}\right) p(\theta) d \theta\right] d \theta^{*} \\
& =u^{\prime}\left(\frac{c_{0}}{\tau F(K)}\right)\left[\frac{1}{\tau F(K)} d c_{0}-\frac{c_{0}}{\tau^{2} F(K)} d \tau\right]
\end{aligned}
$$


First observe that with $\theta$ uniform $p^{\prime}\left(\theta^{*}\right)=0$ and with CRRA preferences, $u^{\prime \prime}\left(\theta-\theta^{*}\right)$ is increasing in $\theta$. Hence the term multiplying $d \theta^{*}$ in $(37)$

$$
\int_{\bar{\theta}}^{\infty} \frac{u^{\prime \prime}\left(\theta-\theta^{*}\right)}{u^{\prime}\left(\bar{\theta}-\theta^{*}\right)}-\frac{u^{\prime \prime}\left(\bar{\theta}-\theta^{*}\right)}{u^{\prime}\left(\bar{\theta}-\theta^{*}\right)} \frac{u^{\prime}\left(\theta-\theta^{*}\right)}{u^{\prime}\left(\bar{\theta}-\theta^{*}\right)} p(\theta) d \theta-\frac{\gamma}{\tau} p^{\prime}\left(\theta^{*}\right) F(K)>0
$$

and with $K$ and parameters $\tau$ and $\gamma$ fixed, (35) defines implicitly a function $\theta_{1}^{*}(\bar{\theta})$ with slope everywhere strictly greater than 1. Likewise, with $K$ and parameters $\tau$ and $\gamma$ fixed, (36) defines implicitly a function $\theta_{2}^{*}(\bar{\theta})$ with positive slope everywhere strictly less than 1 . Since any interior solution of (35) and (36) is found at an intersection of $\theta_{1}^{*}(\bar{\theta})$ and $\theta_{2}^{*}(\bar{\theta})$, any such solution is unique.

We now solve for the comparative statics by analyzing how shifts in the parameters $\tau, \gamma$, and $c_{0}$ shift the implicit functions $\theta_{1}^{*}(\bar{\theta})$ and $\theta_{2}^{*}(\bar{\theta})$. Observe that because the slope of $\theta_{1}^{*}(\bar{\theta})$ is everywhere greater than the slope of $\theta_{2}^{*}(\bar{\theta})$ which in turn is greater than zero, a shift in parameters that raises the function $\theta_{1}^{*}(\bar{\theta})$ and leaves $\theta_{2}^{*}(\bar{\theta})$ unchanged lowers the equilibrium $\theta^{*}$ and $\bar{\theta}$. Moreover, the equilibrium $\bar{\theta}$ falls by more than the equilibrium $\theta^{*}$. Likewise, a shift in parameters that raises $\theta_{2}^{*}(\bar{\theta})$ and leaves $\theta_{1}^{*}(\bar{\theta})$ unchanged raises the equilibrium $\theta^{*}$ and $\bar{\theta}$ and the increase in $\theta^{*}$ is larger than the increase in $\bar{\theta}$.

The comparative statics are the derived as follows. From (37) we see that an increase in $\tau$ lowers $\theta_{1}^{*}(\bar{\theta})$, while from $(38)$ we that that an increase in $\tau$ raises $\theta_{2}^{*}(\bar{\theta})$. The fall in $\theta_{1}^{*}(\bar{\theta})$ by itself raises $\theta^{*}$ and $\bar{\theta}$, with the implied increase in $\bar{\theta}$ larger than the increase in $\theta^{*}$. The increase in $\theta_{2}^{*}(\bar{\theta})$ by itself also raises $\theta^{*}$ and $\bar{\theta}$, but now the implied increase in $\theta^{*}$ is larger than the implied increase in $\bar{\theta}$. Hence we get that an increase in $\tau$ increases both $\bar{\theta}$ and $\theta^{*}$, with the net effect on base pay $\bar{w}=\tau\left(\bar{\theta}-\theta^{*}\right)$ depending on parameters. 
An increase in the manager's reservation utility $U_{0}$, or equivalently an increase in $c_{0}$, only affects $(36)$ and hence $\theta_{2}^{*}(\bar{\theta})$. From $(38)$, we see that an increase in $c_{0}$ lowers $\theta_{2}^{*}(\bar{\theta})$, leading to a fall in $\theta^{*}$ and $\bar{\theta}$, with the fall in $\bar{\theta}$ being smaller than the fall in $\theta^{*}$. Hence, base pay $\bar{w}$ rises.

An increase in the monitoring cost $\gamma$ only affects $(35)$ and hence $\theta_{1}^{*}(\bar{\theta})$. From (37) we see that an increase in $\gamma$ lowers $\theta_{1}^{*}(\bar{\theta})$ and hence raises $\theta^{*}$ and $\bar{\theta}$, with the increase in $\bar{\theta}$ being larger than the increase in $\theta^{*}$. Hence base pay $\bar{w}$ rises. Q.E.D.

In this proposition, we have assumed that the optimal choice of capital is fixed. In general, we cannot obtain analytic comparative statics when capital is variable because the relationship between changes in $\theta^{*}, \bar{\theta}$, and $K$ depends on parameters. This is easiest to see if we assume that preferences are logarithmic, so the first order condition determining the optimal capital stock $K$ reduces to (15). Each of the comparative static exercises we considered above resulted in either an increase in both $\theta^{*}$ and $\bar{\theta}$ or a decrease in both $\theta^{*}$ and $\bar{\theta}$. From (15), however, we see that the impact on the optimal choice of $K$ from an increase in both $\theta^{*}$ and $\bar{\theta}$ is ambiguous - increasing $\theta^{*}$ increases the probability of costly monitoring and hence reduces the optimal choice of $K$ while increasing $\bar{\theta}$ improves risk sharing between the manager and the outside investors and hence increases the optimal choice of $K$. If we assumed that the manager was risk neutral, so that there was no problem of risk sharing between the outside investors and the manager, it would be easy to show that if the manager's reservation utility $c_{0}$ were high enough so that

$$
c_{0}>\tau \int_{0}^{\infty} \theta p(\theta) d \theta F\left(K^{*}\right)
$$


where $K^{*}$ is defined by $F^{\prime}\left(K^{*}\right)=r$, then the optimal contract is fully efficient with no monitoring and the terms of the contract do not change with marginal changes in $\tau, \gamma$, and $c_{0}$. In contrast, when

$$
c_{0}>\tau \int_{0}^{\infty} \theta p(\theta) d \theta F\left(K^{*}\right)
$$

the optimal choice for base pay $\bar{w}$ is zero, so that $\bar{\theta}=\theta^{*}$, and the optimal choices of $\theta^{*}$ and $K$ solve the first order conditions

$$
\begin{aligned}
& \tau F(K) \int_{\theta^{*}}^{\infty}\left(\theta-\theta^{*}\right) p(\theta) d \theta=c_{0} \\
& {\left[1-\gamma P\left(\theta^{*}\right)\right] F^{\prime}(K)=r .}
\end{aligned}
$$

Under this assumption of risk neutrality, an increase in $\tau$ results in an increase in $\theta^{*}$ and a decrease in $K$, an increase in $c_{0}$ results in a decrease in $\theta^{*}$ and an increase in $K$, while an increase in $\gamma$ leads to a decrease in $\theta^{*}$ and a decrease in $K$. 


\section{References}

[1] Aghion, P. and P. Bolton, 1992. An Incomplete Contracts Approach to Financial Contracting, Review of Economic Studies, 59(3): 473-94.

[2] Albuquerque, R. and Hopenhayn, H. "Optimal Lending Contracts and Firm Dynamics", with Hugo Hopenhayn, September 2002. Forthcoming Review of Economic Studies.

[3] Alvarez, F. and U. Jermann, 2000. Efficiency, Equilibrium, and Asset Pricing with Risk of Default, Econometrica, 68(4): 775-97.

[4] Aiyagari, S. Rao, and Fernando Alvarez. "Stationary Efficient Distributions With Private Information and Monitoring: A Tale of Kings and Slaves." Manuscript, Federal Reserve Bank of Minneapolis, 1995.

[5] Atkeson, A., "International Lending with Moral Hazard and Risk of Repudiation," Econometrica, 79:14-31, 1991.

[6] Clementi, G.L. and Hopenhayn, H., "A Theory of Financing Constraints and Firm Dynamics," RCER working paper \#492, June 2002.

[7] Cooley, T., R. Marimon and V. Quadrini, "Aggregate Consequences of Limited Contract Enforceability," Journal of Political Economy, 112(4): 817-847.

[8] DeMarzo, P. and Fishman, M., "Optimal Long-Term Financial Contracting with Privately Observed Cash Flows," Graduate School of Business, Stanford University, 2003.

[9] Dewatripont, M. and J. Tirole. 1994. A Theory of Debt and Equity: Diversity of Securities and Manager-Shareholder Congruence, Quarterly Journal of Economics, 109(4): 1027-54. 
[10] Green, E. "Lending and the Smoothing of Uninsurable Income." In Edward C. Prescott and Neil Wallace, eds., Contractual Arrangements for Intertemporal Trade, pp. 3-25. Minneapolis: University of Minnesota Press, 1987.

[11] Hart, O. and J. Moore. 1995. Debt and Seniority: An Analysis of the Role of Hard Claims in Constraining Management, American Economic Review, 85(3): 567-85.

[12] Hart, O. and J. Moore, 1998. Default and Renegotiation: A Dynamic Model of Debt, Quarterly Journal of Economics, 113(1), 1-41.

[13] Jensen, M. 1986. Agency Costs of Free Cash Flow, Corporate Finance, and Takeovers, American Economic Review, 76(2): 323-29.

[14] Kehoe, T. and D. Levine, 1993. Debt-Constrained Asset Markets, Review of Economic Studies, 60(4): 865-88.

[15] Quadrini, V., "Investment and Default in Optimal Financial Contracts with Repeated Moral Hazard," Stern School of Business, New York University, 2000.

[16] Townsend, R. 1979. Optimal Contracts and Competitive Markets with Costly State Verification, Journal of Economic Theory, 21(2): 265-93.

[17] Wang, C. , 2004. Dynamic Costly State Verification, research memo.

[18] Zweibel, J. 1996. Dynamic Capital Structure under Managerial Entrenchment, American Economic Review, 86 (5), 1197-1215. 